\title{
Notas sobre o efeito da variação da taxa de câmbio sobre o lucro de uma firma exportadora
}

\author{
Notes on the effects of exchange \\ rate variation on the profits of an \\ exporting firm
}

Antonio Sergio Munhoz ${ }^{1}$

Palavras-chave: taxa de câmbio; firma exportadora; lucros.

Key words: exchange rate; exporting firm; profits.

JEL: L25, Coo, F31

\section{Introdução}

O objetivo deste trabalho é fazer uma análise do efeito das variações da taxa de câmbio sobre o lucro de uma firma exportadora sob um mercado sujeito a algumas restrições. Trata-se de um trabalho que requer derivação matemática elementar e, embora sujeito a hipóteses restritivas, tem consequiências quantitativas relevantes para explicar o impacto do câmbio no lucro das firmas exportadoras.

Relacionadas com o tema, existem muitas análises econométricas sobre o que a literatura chama de exposição ao câmbio. Entre estas, citamos Dominguez e Tesar (2001) que avaliam a exposição ao câmbio de um universo de firmas por meio de um modelo de regressão linear da rentabilidade das ações da firma em relação à rentabilidade de uma car- 
teira de mercado e à variação na taxa de câmbio. Então consideram que uma firma tem exposição ao câmbio se o coeficiente do termo de variação do câmbio é, significativamente, diferente de zero. Adotando uma abordagem um pouco diferente, Pritamani, Shome e Singal (2005) separam o universo de firmas em firmas exportadoras e firmas importadoras, concluindo que a valorização da moeda local tem um efeito negativo sobre a rentabilidade das ações das firmas exportadoras significativamente maior do que o efeito sobre as firmas não exportadoras.

A abordagem adotada aqui é mais fundamentalista e preocupa-se com o fato não irrelevante, que aparentemente foi pouco explorado na literatura, de que firmas exportadoras, em geral, são afetadas pelo câmbio nas duas direções, seja do lado da compra de insumos internos ou pagamento de juros relativos a financiamento interno, seja do lado da venda, compra de insumos externos ou pagamento de juros de dívidas em moeda estrangeira.

\section{Hipóteses}

Consideremos uma firma exportadora que esteja sujeita às seguintes restrições:

R1. comercializa um único produto a um preço constante em moeda estrangeira e a uma taxa constante em termos de unidades vendidas por unidade de tempo;

R2. os custos totais incorridos pela firma para produzir uma unidade do produto estão divididos em custos de fatores adquiridos internamente em moeda nacional que consideraremos o real e em custos de fatores adquiridos externamente em moeda estrangeira que consideraremos o dólar, sendo o montante de cada tipo de custo constante.

\section{Notação}

De acordo com as hipóteses, podemos definir as constantes $P$, o preço de uma unidade do produto, $N$, a quantidade comercializada em uma unidade de tempo, $\alpha_{1}$, o custo dos fatores internos incorridos em real e $\beta_{1}$, o custo de fatores externos incorridos em dólar para cada unidade de produto.

Se $L d$ é o lucro econômico em dólar e $x$, a taxa de câmbio em reais por unidade de dólar, então: 


$$
L d=N\left(P-\beta_{1}-\frac{\alpha_{1}}{x}\right)
$$

Obviamente, o lucro econômico em real vale:

$$
L r=N\left(P-\beta_{1}-\frac{\alpha_{1}}{x}\right) x
$$

Sejam agora $\boldsymbol{\alpha}$ e $\boldsymbol{\beta}$, respectivamente, os custos internos de fatores em real e os custos externos de fatores em dólar para cada dólar unitário de produto comercializado, isto é:

$$
\alpha=\alpha_{1} / P \quad \text { e } \beta=\beta_{1} / p
$$

Assim, vemos que o lucro econômico em dólar é proporcional ao que chamaremos de lucro em dólar por dólar de produto vendido e representaremos por $l d$ :

$$
l d=1-\beta-\frac{\alpha}{x}
$$

Analogamente, o lucro em real por dólar vendido, $l r$, é:

$$
l r=(1-\beta) x-\alpha
$$

Notemos que tanto o lucro econômico em dólar é proporcional ao lucro em dólar por dólar de produto vendido quanto o lucro econômico em real é proporcional ao lucro econômico em real por dólar de produto vendido, com constante de proporcionalidade igual a $N P$.

\section{Resultado principal}

Com a mesma notação acima, temos:

$$
\begin{aligned}
& \frac{d}{d x} l d=\frac{\alpha}{x^{2}} \\
& \frac{d}{d x} l r=1-\beta
\end{aligned}
$$

Consideremos a seguinte situação hipotética. O câmbio encontra-se, inicialmente, ao valor de 2 reais/dólar, situação em que a firma gasta 1 real com custos internos para cada dólar de produto exportado e 0.25 dólares para cada dólar de produto exportado. De acordo com as relações obtidas, temos:

$$
\frac{d}{d x} l d=\frac{1}{x^{2}} \quad \text { e } \frac{d}{d x} l r=0.75
$$


Portanto, quanto mais o câmbio cresce, supondo que estejamos sob as restrições R1 e R2, menos o lucro em dólar por dólar de produto exportado é afetado pela variação do câmbio, embora o lucro em real por dólar de produto exportado tenha uma taxa independente do câmbio. Por exemplo, se a taxa de câmbio passar para 3 reais/dólar, pequenas oscilações em torno dela terão efeito pouco pronunciado no lucro em dólar por dólar de produto exportado. Além disso, com a variação do câmbio, $l r$ vai de 0.50 para 1.25 e $l d$ varia muito menos, indo de 0.25 para 0.42 .

Para comparar o efeito do câmbio na rentabilidade das ações de uma firma exportadora que participe da bolsa de valores local e da bolsa de valores do país moeda estrangeira, é conveniente calcular as elasticidades do lucro em moeda local e em moeda estrangeira em relação ao câmbio, a que chamaremos, respectivamente, de $e r$ e $e d$ :

$$
\begin{aligned}
& e r=\frac{d L r / L r}{d x / x} \\
& e d=\frac{d L d / L d}{d x / x}
\end{aligned}
$$

Sendo $\mathrm{R}=\mathrm{NP}$, a receita bruta da firma em moeda estrangeira, que é constante devido às hipóteses, temos $L r=R l r, L d=R l d \mathrm{e}$ :

$$
\begin{aligned}
& e r=\frac{d l r / l r}{d x / x}=\frac{x(1-\beta)}{(1-\beta) x-\alpha} \\
& e d=\frac{d l d / l d}{d x / x}=\frac{\alpha}{(1-\beta) x-\alpha}
\end{aligned}
$$

e, portanto:

$$
e d=\frac{\alpha}{(1-\beta)} \frac{1}{x} e r
$$

Quando a moeda local está desvalorizada a ponto de

$$
x>\alpha /(1-\beta)
$$

a elasticidade em relação à moeda estrangeira é menor que a elasticidade em relação à moeda local, o que significa que o lucro da firma exportadora em moeda local torna-se mais sujeito aos efeitos do câmbio do que o lucro em moeda estrangeira. Uma vez que a variação do lucro é um determinante importante das cotações das ações de uma firma em bolsa, a variação do câmbio tende a ter um impacto menor nos preços das ações negociadas em bolsa local do que em bolsa estrangeira. 
Observemos que, para o exemplo em questão, quando o câmbio é de 2 reais/dólar, $e d=1 /(1-0.25) 1 / 2=2 / 3 \mathrm{er}$ e, quando o câmbio é de 3 reais/dólar, $e d=4 / 9 \mathrm{er}$.

No Brasil, nos últimos anos, o crescimento das exportações mais fortemente do que as importações, tem valorizado o real, o que tem prejudicado, principalmente, de acordo com estudo da Unidade de Política Econômica da CNI (2005), as empresas que têm custos locais elevados, por exemplo, as intensivas em mão-de-obra, como é o das indústrias de vestuário e de calçados. Isso concorda com o previsto aqui, já que a elasticidade do lucro em moeda local é maior para firmas exportadoras que tem $\alpha /(1-\beta)$ mais alto, pois:

$$
\partial / \partial(\alpha /(1-\beta)) e r=\frac{x}{(x-\alpha /(1-\beta))^{2}}
$$

é sempre positivo, e também porque er é mais sensível a $\alpha$ do que a $\beta$ quando

$$
\alpha /(1-\beta)>1
$$

já que

$$
\partial(\alpha /(1-\beta)) / \partial \alpha=\frac{\alpha}{1-\beta} \partial(\alpha /(1-\beta)) / \partial \beta
$$

Vale notar que $\alpha$ e $\beta$ estão sujeitos a variações devido às modificações nas economias local e internacional que acabam por tornar a hipótese de preços e quantidades comercializadas constantes insustentável, entretanto, devido à circunstância comum de os contratos de compra e venda das empresas serem firmados em prazos consideravelmente longos, esses parâmetros tendem a se manter constantes em períodos curtos. Portanto, esses parâmetros tornar-se-iam indicadores, pelo menos no curto prazo, de quais firmas estariam sujeitas mais fortemente ao risco cambial e teriam maior necessidade de utilização de instrumentos de hedge. Entretanto, tais fatos carecem de uma análise econométrica cuidadosa do mercado a fim de serem comprovados, o que poderia ser uma continuação deste trabalho.

\section{Conclusões}

Avaliamos, de forma quantitativa, a dependência do lucro de uma firma exportadora seja em moeda local, seja em moeda estrangeira em relação ao câmbio, enfatizando a influência da divisão dos custos dos fatores entre os que são pagos em moeda local e moeda estrangeira. Dessa forma, com as relações obtidas, quando as hipóteses de trabalho são 
válidas, tornou-se possível comparar a sensibilidade do lucro em moeda local e em moeda estrangeira, levando em conta o efeito da divisão dos custos. Como possível desdobramento deste trabalho, citamos uma avaliação econométrica da validade das conclusões tendo em vista o mercado real e estimativas dos parâmetros utilizados aqui para as firmas exportadoras do mercado nacional ou internacional.

\section{Referências}

MAIA, J. M.(2003). Economia internacional e comércio exterior. São Paulo: Editora Atlas.

WILLIAMSON, J.(1989). A economia aberta e a economia mundial. Rio de Janeiro: Editora Campus.

DOMINGUEZ, K.M.E. \& TESAR, L.L. (2001). “Trade and exposure.” Papers and Proceedings of American Economic Review May: 367-370.

PRITAMANI, M. \& SHOME, D. \& SINGAL, V. (2005), "Exchange rate exposure of exporting and importing firm." Journal of Applied Corporate Finance 17 (3):87-94.

UNIDADE DE POLÍTICA ECONÔMICA - CNI (2005). “Os efeitos da valorização do real na indústria brasileira.” URL [On line]: http://www.cni.org.br/ produtos/econ/src/efeitos_valorizacao_real.pdf. Acesso em: 19 de fevereiro de 2007.

Recebido em: 17 jan. 2007

Aceite em: 22 fev. 2007 